\title{
Aproximación jurídica internacional al ejercicio de la jurisdicción civil universal frente a violaciones graves de derechos humanos
}

\author{
The exercise of universal civil jurisdiction for serious \\ human rights violations
}

Jordi Bonet Pérez

Universitat de Barcelona

jbonet@ub.edu

doi: http://dx.doi.org/10.18543/djhr.1791

Fecha de recepción: 30.01.2020

Fecha de aceptación: 20.05.2020

Cómo citar/Citation: Bonet, Jordi. 2020. «Aproximación jurídica internacional al ejercicio de la jurisdicción civil universal frente a violaciones graves de derechos humanos». Deusto Journal of Human Rights, n. 5 : 13-40. doi: http://dx.doi.org/10.18543/djhr.1791

Sumario: Introducción. 1. La jurisdicción civil universal en el Derecho internacional general. 1.1. La práctica estatal y la regulación en el Derecho internacional general de la jurisdicción civil universal. 1.2. Implicaciones de la afirmación del derecho a la justicia en Derecho internacional general. 2. El Derecho internacional privado como fundamento del ejercicio extraterritorial de la jurisdicción civil. 2.1. La instrumentalidad del Derecho internacional privado ante violaciones graves de derechos humanos. 2.2. El foro de necesidad y la competencia respecto a la acción civil. Consideraciones finales. Bibliografía.

Resumen: No es reconocible ni en el Derecho internacional general ni en el convencional una obligación jurídica internacional que exija el ejercicio de la jurisdicción civil universal frente a violaciones graves de derechos humanos. Considerando que su implementación no está prohibida (principio permisivo), parece necesario conciliar el alcance de las jurisdicciones estatales con el derecho a la justicia de las víctimas, lo que comporta un compromiso solidario erga omnes de evitar la denegación de justicia a toda víctima. El Derecho internacional privado puede ofrecer cauces para garantizar ese acceso y, en ese sentido, el foro de necesidad como institución subsidiaria (residual) es uno de ellos. Sin embargo, visto el asunto Naït-Liman c. Suiza ante el Tribunal Europeo de Derechos Humanos, los requisitos para encauzar una reclamación mediante el foro de necesidad pueden llegar a ser un impedimento excesivo desde el prisma del derecho a la justicia. 
Palabras clave: jurisdicción universal, extraterritorialidad, foro de necesidad, violaciones graves de derechos humanos, responsabilidad civil

Summary: It seems that there is no international legal obligation, neither in international treaties nor in general international law, that confirms the existence of state legal obligations on the exercise of universal civil jurisdiction against gross violations of human rights. However, while its implementation is not prohibited (thanks to the permissive principle), it seems necessary to reconcile the state jurisdiction with the right to justice of victims, which creates a shared erga omnes commitment to prevent the denial of justice. Private international law offers jurisdictional paths that have served to ensure such access in practice and, in this sense, the forum of necessity, as a alternative institution, would be perhaps one of the most effective means. As the NaïtLiman v. Switzerland case presented before the European Court of Human Rights demonstrate, though, the requirements prescribed to submit a claim through the necessity forum can become an excessive burden from the point of view of the right to justice.

Keywords: universal jurisdiction, extraterritoriality, forum of necessity, serious violations of human rights, civil liability. 


\section{Introducción ${ }^{1}$}

Igual que el establecimiento y ejercicio de la jurisdicción penal universal se sustenta "exclusivamente en la naturaleza del delito», prescindiendo «del lugar en que éste se haya cometido, la nacionalidad del autor presunto o condenado, la nacionalidad de la víctima o todo otro nexo con el Estado que ejerza esa jurisdicción»², la jurisdicción civil universal perfila «un domaine de compétence à raison de la matière», no delimitado por consideraciones de conexión ratione personae o ratione loci con el foro (Bucher 2015, 101) y cuyo ejercicio no «depende de ningún factor o vínculo de conexión» con los hechos lesivos (Ferrer 2019, 25).

Apelando a la noción jurídica internacional clásica de jurisdicción —dominio prescriptivo reflejado en el ejercicio de la autoridad judicial y ejecutiva-, la implementación de la jurisdicción civil universal se conecta con la extensión del alcance extraterritorial tanto del ordenamiento jurídico interno como de la competencia judicial que garantice su aplicación. El Derecho internacional público puede autorizar o exigir el ejercicio extraterritorial de la jurisdicción en determinados supuestos, entre ellos, aquellas conductas que -como pueden ser las violaciones graves de derechos humanos- vulneran «principles of universal concern» (Cleveland 2010, 232).

Mientras la jurisdicción penal universal «has found broad support in international law» (Brus 2014, 366) ${ }^{3}$, cabe preguntarse si, paralelamente, existen para los Estados obligaciones jurídicas internacionales que les exijan garantizar el ejercicio de la jurisdicción civil universal frente a violaciones graves de derechos humanos. Tal tipo de acción es diferenciable de la subsidiaria reclamación de responsabilidad civil dentro de un proceso penal ${ }^{4}$.

1 El artículo se enmarca en el Proyecto de investigación La territorialidad como límite de la jurisdicción del Estado ante conductas de actores privados no estatales que repercuten en la efectividad de los derechos humanos internacionalmente reconocidos (DER2015-67026-P), financiado por el Ministerio de Economía y Competitividad.

2 Principios de Princeton sobre la Jurisdicción Universal, de 27 enero 2001 (Principio 1,1).

3 Aunque no existan argumentos para sostener que la jurisdicción penal universal haya sido generalmente aceptada (fuera de las realizaciones convencionales existentes), hay "certain indications that a universal crime jurisdiction for certain international crimes is clearly not regarded as unlawful» (Joint separate opinion of Judges Higgins, Kooijmans and Buergenthal, § 45, Arrest Warrant of 11 April 2000 (Democratic Republic of the Congo v. Belgium, Judgment, I.C.J. Reports 2002).

4 El art. 71 del Estatuto de la Corte Penal Internacional señala que esta «podrá dictar directamente una decisión contra el condenado en la que indique la reparación adecuada que ha de otorgarse a las víctimas». 
Su fundamento axiológico y político-jurídico recae, tanto en la necesidad de garantizar la ejecución de obligaciones jurídicas concernientes a la vulneración de normas jurídicas internacionales esenciales para el respeto de la dignidad humana (derecho a la reparación de las víctimas), como en la necesidad de que las víctimas dispongan de recursos judiciales efectivos a su alcance; considerando, además, la particular y habitual centralidad de la iniciativa de las víctimas en los procesos civiles (Ryngaert 2017, 206).

La identificación de las violaciones graves de derechos humanos con el respeto a la dignidad humana facilita, que no soluciona, la cuestión de su delimitación. Pueden servir de orientación los trabajos en el seno de la Organización de Naciones Unidas (ONU): el proyecto de Declaración que defina las violaciones manifiestas y masivas de los derechos humanos como crímenes internacionales, dirigida a concretar en materia de derechos humanos el concepto de crimen internacional del artículo 19 del Proyecto de Artículos sobre la responsabilidad internacional del Estado (1996) ${ }^{5}$, así como la noción de gravedad formulada por la CDI6.

Este estudio plantea una doble aproximación: a la jurisdicción civil universal en el Derecho internacional general; y al Derecho internacional privado como fundamento del ejercicio extraterritorial de la jurisdicción civil.

5 En concreto: a) asesinato, incluida la ejecución arbitraria; b) tortura; c) genocidio; d) apartheid; e) discriminación por motivos raciales, nacionales, étnicos, lingüísticos o religiosos; f) establecimiento o mantenimiento de personas en estado de esclavitud, servidumbre o trabajo forzoso; g) desapariciones forzosas o involuntarias; h) detención arbitraria y prolongada; i) deportación o traslado forzoso de poblaciones (ONU, «Definición de las violaciones manifiestas y masivas de los derechos humanos como crímenes internacionales Documento de trabajo presentado por el Sr. Stanislav Chernichenko de conformidad con la decisión 1992/109 de la Subcomisión», Documento E/CN.4/ Sub.2/1993/10, 8 de junio de 2003, p. 6, párr. 17).

6 La noción de gravedad de la CDI, vinculado a la vulneración de normas imperativas del art. 40, 2 del Proyecto de artículos sobre la responsabilidad del Estado por hechos internacionalmente ilícitos (2001), abarca el incumplimiento flagrante (intensidad del ataque a los valores que protege la norma) o sistemático (violación llevada a cabo de manera deliberada y organizada) de un obligación jurídica internacional; entre "los factores que permiten establecer la gravedad de una violación estarán la intención de violar la norma», "el alcance y el número de violaciones individuales» y «la gravedad de sus consecuencias para las víctimas» (CDI, Informe de la Comisión de Derecho Internacional, $53^{\circ}$ período de sesiones (23 de abril a 1 de junio y 2 de junio a 10 de agosto de 2001), Documento A/56/10, Suplemento 10, p. 308, párr. 8). 


\section{La jurisdicción civil universal en el Derecho internacional general}

Se abordarán seguidamente la práctica estatal y la regulación en el Derecho internacional general de la jurisdicción civil universal y las implicaciones de la afirmación del derecho a la justicia en Derecho internacional general.

\subsection{La práctica estatal y la regulación en el Derecho internacional general} de la jurisdicción civil universal

Para el reconocimiento como parte del Derecho internacional general de una costumbre internacional que pudiera obligar jurídicamente a los Estados a ejercer la jurisdicción civil universal frente a violaciones graves de derechos humanos resulta indispensable (CDI 2014, 8, pár. 22) cerciorarse de que exista "una práctica general ["suficientemente extendida y representativa, además de constante»] que es aceptada como derecho (opinio juris)» (CDI 2016, 1 y 3, Proyecto de conclusiones números 1 y 8 ).

La necesidad de valorar la práctica estatal para identificar una costumbre internacional subraya que la inspiración axiológica y político-jurídica del principio general de Derecho internacional del respeto a la dignidad humana no basta para consecuencialmente positivizar una norma de Derecho internacional general que exija el ejercicio de la jurisdicción civil universal. Asimismo, permite afirmar que tampoco: 1) puede prescindirse de ella por aceptar un enfoque sectorial del Derecho internacional de los derechos humanos (CDI 2014, 12-13, pár. 28) para probar que, en este ámbito material, existe una exigencia jurídica consuetudinaria de establecerla y ejercerla — pese al mayor peso otorgado a la opinio iuris ante una práctica estatal que refleja "too many violations to serve as a sound basis of induction» (Kolb 2003, 124) -; y 2) basta admitir que las violaciones graves de derechos humanos, en buena medida, se vinculan a prohibiciones previstas en normas imperativas de Derecho internacional, que no admiten pacto en contrario y que expresan un interés esencial de la Comunidad internacional en su conjunto (Comité de Derechos Humanos 2001, p. 6, pár. 11). La Corte Internacional de Justicia (CIJ) ha afirmado que las normas jurídicas internacionales primarias, como la prohibición imperativa de la tortura, no desvirtúan la aplicabilidad de las normas jurídicas internacionales de naturaleza procesal, como las relativas a la 
inmunidad jurisdiccional de los Estados ${ }^{7}$ — constituida jurídicamente en una "significant barrier to the recovery of damages for victims of human rights violations» (Besner y Attaran 2008, 166).

El carácter consuetudinario o no de esta hipotética norma jurídica internacional exige una aproximación a una práctica estatal, particular y específica (no deducida de la naturaleza jurídica imperativa de la normativa primaria con la que se relaciona).

a) En Estados Unidos de América, la Aliens Tort Act ${ }^{8}$ ha tendido a ser interpretada restrictivamente por el Tribunal Supremo en lo concerniente a la extraterritorial de la acción civil por violación de derechos humanos, sobre todo en los asuntos Sosa c. Alvarez-Machain y Kiobel c. Royal Dutch Pretrolium, aunque el filtro de admisibilidad que supone la presunción contra la extraterritorialidad haya sido modulada por los Tribunales Federales mediante el Touch and Concern Test ${ }^{9}$ (Marullo y Zamora 2018, 236). Existe, además, una acción civil extraterritorial específica para la tortura y las ejecuciones extrajudiciales en la Torture Victim Protection Act (TVPA), con ciertas condiciones: puede instarla cualquier persona física (previo agotamiento de los recursos internos en el lugar de los hechos y con una caducidad de la acción de 10 años «after the cause of action arose»), incluidos los ciudadanos estadounidenses, frente a conductas de otra persona física, a instancias o bajo cualquier autoridad extranjera. Parecen excluirse los actos cometidos por empresas privadas pero los Tribunales Federales no han descartado de modo radical que esta acción civil pueda dirigirse contra personas jurídicas (Marullo y Zamora 2018, 246).

b) En Canadá, tal y como a nivel quebequés demuestra su Código Civil $^{10}$, es potencialmente factible una acción civil extraterritorial

7 Jurisdictional Immunities of the State (Germany v. Italy: Greece intervening), Judgment, I.C.J. Reports 2012, p. 141, pár. 95.

828 USC § 1350; apartado que incluye la Torture Victim Protection Act.

9 Si la primera decisión limita la acción a las más graves violaciones de derechos humanos, la segunda postula una presunción general contra la extraterritorialidad de las leyes, desmontable si: «(1) l'acte illicite allégué est survenu sur le territoire américain, (2) le défendeur est américain, ou (3) que le comportement du défendeur affecte de manière sensible et défavorable un important intérêt national américain, ce qui comprend un intérêt net à empêcher que les Etats-Unis deviennent un havre sûr (libéré de la responsabilité civile et pénale) pour un tortionnaire ou tout autre ennemi de l'humanité» (Bucher 2015, 27).

10 Arts. 3148,2 (competencia por acción civil contra persona jurídica no domiciliada pero con establecimiento en Quebec cuando la reclamación sea relativa a su actividad en Quebec) y 3136 (foro de necesidad). 
por violaciones graves de derechos humanos - aunque no resulte sencilla su admisión en la práctica-11; perfilándose la posibilidad de una acción civil, frente a actos de tortura infligidos por personas incluibles en la definición del artículo 1,1 CAT ${ }^{12}$, aunque restringida a aquellos actos a los que fuese aplicable la excepción a la inmunidad jurisdiccional del Estado prevista en la State Immunity Act: su vínculo con «certain foreign states [incluidos «on a list created by the Governor in Council] that have supported terrorist activity» con posterioridad a 1 de enero de $1985^{13}$.

c) En los Países Bajos, las acciones civiles «can be brought against a defendant for alleged human rights violations or environmental harms, regardless of the location of the harms or the domicile or nationality of the victims, as long as the defendant has a domicile or its headquarters in the Netherlands» (Jägers et al. 2014, 39). El Tribunal de Apelación de La Haya ${ }^{14}$ justificó su jurisdicción tanto sobre los comportamientos de la empresa matriz registrada en Países Bajos (artículos 2,1 y 60,1 del Reglamento 44/2001)15, como de la empresa radicada en Nigeria. Sus argumentos sobre "the potential liability of the parent company for the conduct of its subsidiaries» son calificados de sólidos (Bright 2019, 220).

En un caso de tortura en el extranjero por autoridades foráneas (Wind 2018: 31), el ejercicio de la jurisdicción civil se fundó en el foro de necesidad (véase Apartado III, 2), alegable

11 Véase el fallido intento en la Corte de Apelación quebequesa (Anvil Mining Ltd. c. Association canadienne contre l'impunité, 2012 QCCA 117), ante la falta de vinculación con el territorio de las actividades de la persona jurídica establecida en Quebec (foro ordinario) o no demostrarse la imposibilidad de plantear el litigio ante otras jurisdicciones (foro de necesidad).

12 Cualquier «funcionario público u otra persona en el ejercicio de funciones públicas, a instigación suya, o con su consentimiento o aquiescencia».

13 Kazemi Estate v. Islamic Republic of Iran, 2014 SCC 62, [2014] 3 S.C.R. 176, en 208 (pár. 44).

14 Gerechtshof Den Haag, Eric Barizaa Dooh et al. c. Royal Dutch Shell PLC (RDS) and Shell Petroleum Development Company of Nigeria Ltd. (SPDC), 18-12-2015 / 200.126.843-01 / 200.126.848-01.

15 Reglamento (CE) n. ${ }^{\circ} 44 / 2001$ del Consejo, de 22 de diciembre de 2000, relativo a la competencia judicial, el reconocimiento y la ejecución de resoluciones judiciales en materia civil y mercantil; derogado por el Reglamento (UE) n. ${ }^{\circ}$ 1215/2012 del Parlamento Europeo y del Consejo, de 12 de diciembre de 2012, relativo a la competencia judicial, el reconocimiento y la ejecución de resoluciones judiciales en materia civil y mercantil. 
sin exigencia de vínculo particular con el foro (Jägers et al. 2014, 38-39) ${ }^{16}$, a diferencia de lo habitual en otras legislaciones comparadas que estipulan esta institución (Bucher 2015, p. 36) ${ }^{17}$.

d) La experiencia del Reino Unido es similar ante violaciones graves de derechos humanos vinculadas a riesgos medioambientales: por ejemplo, la confirmación el 10 de abril de 2019 por la Corte Suprema del Reino Unido de la competencia de los tribunales británicos en el asunto Vedanta ${ }^{18}$, por las actividades de la filial zambiana de la apelante, a tenor del artículo 4 del Reglamento (UE) n. ${ }^{\circ} 1215 / 2012^{19}$.

Como en Canadá, los tribunales mantienen la inmunidad jurisdiccional del Estado y sus agentes frente acciones civiles: en el asunto Jones v. Arabia Saudí, Lord Bingham of Cornill afirmó que la Convención de $2004^{20}$ y, a resultas, el Derecho internacional general, no negaban la «state immunity in cases where jus cogens norms of international» hubieran sido violadas fuera del Estado del foro ${ }^{21 .}$

e) En lo que concierne al resto de Estados europeos, la práctica estatal que reconoce el Tribunal Europeo de Derechos Humanos (TEDH) en 39 países europeos (incluida España)22, lleva a concluir que los Estados Partes «[salva aquí la excepción holandesa] do

16 Rechtbank 's-Gravenhage, El-Hojouj v. Unnamed Libyan Officials, Mar. 21, 2012, Case No.400882/HA ZA 11-2252.

17 El art. 9 del Código de Procedimiento Civil holandés prevé: «When Articles 2 up to and including 8 indicate that Dutch courts have no jurisdiction, then they nevertheless have if: (...) b. a civil case outside the Netherlands appears to be impossible».

18 Vedanta Resources PLC and another (Appellants) $v$ Lungowe and others (Respondents [2019] UKSC20 on appeal from: Lungowe \& Ors v Vedanta Resources Plc \& Anor [2017] EWCA Civ 1528 (13 October 2017).

19 «1. Salvo lo dispuesto en el presente Reglamento, las personas domiciliadas en un Estado miembro estarán sometidas, sea cual sea su nacionalidad, a los órganos jurisdiccionales de dicho Estado.

2. A las personas que no tengan la nacionalidad del Estado miembro en que estén domiciliadas les serán de aplicación las normas de competencia judicial que se apliquen a los nacionales de dicho Estado miembro».

20 Convención sobre las Inmunidades Jurisdiccionales de los Estados, y de sus bienes.

21 Jones v. Ministry of Interior Al-Mamlaka Al-Arabiya AS Saudiya (the Kingdom of Saudi Arabia) and others [2006] UKHL 17, § 26; "there is no evidence that states have recognised or given effect to an international law obligation to exercise universal jurisdiction over claims arising from alleged breaches of peremptory norms of international law» (ibid. § 27).

22 Véase la sentencia en primera instancia de la Sala: Naït-Liman v. Switzerland, no. 51357/07, §§ 48-76, 21 June 2016. 
not recognise universal international jurisdiction before the civil courts, whether for acts of torture or for other criminal acts or offences» ${ }^{23}$.

Todo ello lleva a una conclusión negativa sobre la extensión de la práctica estatal y «la existencia de un consensus generalis sobre la vigencia o no de una norma de Derecho internacional general que obligue a la jurisdicción civil universal» (Ferrer 2019, 30), porque los Estados que la aplican son la excepción.

El contenido y la práctica relativas a tratados internacionales de carácter universal y específico como la Convención contra la Tortura y Otros Tratos o Penas Crueles, Inhumanos o Degradantes (CAT) o la Convención Internacional para la protección de todas las personas contra las desapariciones forzadas (CDF) —artículos 1424 y 24,425, respectivamente- no son diáfanas respecto a la exigibilidad jurídica de la jurisdicción civil universal para garantizar una indemnización justa en favor de cualquier víctima, incluso acudiendo a las reglas de interpretación de los artículos 31-33 del Convenio de Viena sobre el Derecho de los Tratados (CVDT).

A diferencia de otras disposiciones convencionales - por ejemplo, artículo 2,1 CAT26_- el artículo 14 CAT no incluye expresamente un límite territorial o de ámbito jurisdiccional, por lo que de su literalidad parece desprenderse que exige al Estado Parte garantizar a toda víctima una vía de reclamación indemnizatoria «regardless of where it occurred» (Hall 2007, 923). No obstante, autores significados señalan que solo obliga jurídicamente al Estado Parte «which actually bears responsibility for the torture inflicted» (Nowak 2007, 169); sin perjuicio de que el párrafo 2 permita instituir un procedimiento civil universal,

23 Naït-Liman v. Switzerland [GC], no. 51357/07, § 70, ECHR 2018.

24 «1. Todo Estado Parte velará porque su legislación garantice a la víctima de un acto de tortura la reparación y el derecho a una indemnización justa y adecuada, incluidos los medios para su rehabilitación lo más completa posible. En caso de muerte de la víctima como resultado de un acto de tortura, las personas a su cargo tendrán derecho a indemnización.

2. Nada de lo dispuesto en el presente artículo afectará a cualquier derecho de la víctima o de otra persona a indemnización que pueda existir con arreglo a las leyes nacionales.

25 «Los Estados Partes velarán por que su sistema legal garantice a la víctima de una desaparición forzada el derecho a la reparación y a una indemnización rápida, justa y adecuada».

26 «Todo Estado Parte tomará medidas legislativas, administrativas, judiciales o de otra índole eficaces para impedir los actos de tortura en todo territorio que esté bajo su jurisdicción». 
pues ni su redacción ni el Derecho internacional general lo prohíben (Ryngaert 2007, 19). El debate es menos intenso respecto al artículo 24,4 CDF, pues, durante los trabajos preparatorios, se señaló que «no imponía la responsabilidad legal del Estado si éste no estaba implicado en un acto de desaparición» (Comisión de Derechos Humanos 2006, 28, pár. 142).

Particularmente, sobre la interpretación de la CAT cabe decir:

a) Parece ilógico exigir la disponibilidad de una jurisdicción civil de alcance más extensivo y universal que lo previsto para la jurisdicción penal en los artículos 5 a 8 CAT (Bucher 2015, 48-50): el artículo 5 CAT extiende la persecución a actos cometidos fuera del territorio o jurisdicción solo si la víctima es nacional del Estado Parte y este lo considera apropiado (por lo que existe un poder decisorio del Estado en función de sus intereses), o si el presunto responsable es nacional o se encuentra en un territorio bajo su jurisdicción.

b) El argumento del Presidente estadounidense Ronald Reagan, considerando un error eliminar en el borrador de proyecto la restricción territorial introducida previamente a instancia de los Países Bajos (US Senate 1990, 24), parece no resistir un análisis profundo de los trabajos preparatorios (Burgers y Danelius 1988, 146-147).

c) La práctica subsiguiente de los Estados Partes muestra cómo no parecen proclives a extender su jurisdicción a actos de tortura no producidos en su territorio o bajo su jurisdicción. Si Bahamas, Bangladesh, Fiji, Nueva Zelanda o Samoa se remitieron a su legislación o a la discreción de sus tribunales, la declaración interpretativa de los Estados Unidos de América (asimilable quizá a una reserva de modificación) señalaba que el artículo 14 CAT predicaba «to provide a private right of action for damages only for acts of torture committed in territory under the jurisdiction of that State Party ${ }^{27}$. Estados Partes, como Canadá —ajustándose a la decisión jurisdiccional en el asunto Bouzari28 (Comité contra la Tortura 2016, 44,

27 La ratificación «is subject to the following understandings, which shall apply to the obligations of the United States under this Convention» (United Nations Treaty Collection, Status of Treaties. Convention against Torture and Other Cruel, Inhuman or Degrading Treatment or Punishment, p. 7. Acceso 30 diciembre 2019, https://treaties. un.org/doc/Publication/MTDSG/Nolume\%20I/Chapter\%20IV/IV-9.en.pdf).

28 Court of Appeal for Ontario, Houshang Bouzari, Fereshteh Yousefi, Shervin Bouzari and Narvan Bouzari v. Islamic Republic of Iran [2004] OJ No. 2800, pár. 83. 
pár. 187)—, Australia (Comité contra la Tortura 2015, 5, pár. 4.3) o España (Comité contra la Tortura 2002, 208, pár. 4.4.) se han pronunciado en la misma dirección. La práctica estatal respecto a la CAT, por consiguiente, corrobora la tendencia previamente apuntada.

d) El órgano de expertos independientes es muy ambiguo, como demuestra la redacción de su Observación General núm. 3 (Comité contra la Tortura 2012b, 6, pár. 22): si bien asume que el artículo 14 CAT no se circunscribe a las víctimas de daños infligidos en el territorio del Estado Parte, se limita a encomiar (has commended) los esfuerzos de los Estados Partes por disponer de recursos civiles para víctimas de torturas fuera de su territorio. Asimismo, cuando identifica los obstáculos a la efectividad del artículo 14 CAT, tampoco suele mencionar específicamente este extremo, pese a la generalizada práctica estatal negativa (Comité contra la Tortura 2012a, 9, pár. 38).

En consecuencia, no se puede concluir del texto del artículo 14,1 CAT si exige al Estado Parte «to provide a cause of action for all acts of torture» (Mora 2009, 373 y 378).

\subsection{Implicaciones de la afirmación del derecho a la justicia en Derecho internacional general}

En apariencia, solo la legislación estadounidense, más allá de los filtros restrictivos (Requejo 2007, 541), formaliza mediante la Aliens Tort Act una jurisdicción civil con tendencias potencialmente universalistas respecto a violaciones graves de derechos humanos (Mora 2018, 171) y una modalidad específica menos limitativa sobre tortura y ejecuciones extrajudiciales (TVPA) ${ }^{29}$.

El ejercicio de la jurisdicción civil en Países Bajos o Reino Unido examinada no es fruto de una prescripción específica y jurídicoformal atributiva de competencia civil universal, sino de soluciones de Derecho internacional privado estatales o comunitarias, más o menos restrictivas, para litigios sobre atribución de competencia jurisdiccional civil, conforme a la lógica de su objeto: resolver «disputes of a civil and commercial nature that have contact with a municipal legal

29 TVPA «creates a cause of action against any individual who under authority, or colour of law, subjects another individual to torture or extrajudicial killing in a foreign jurisdiction» (Mora 2018, 171). 
system different to that of the forum State in which the proceedings are brought» (Mora, 2018: 160).

Las normas jurídicas que otorgan la competencia judicial civil a estos dos Estados relativizan y/o flexibilizan las exigencias de vinculación con el foro, por lo que se aproximan funcionalmente al ejercicio de la jurisdicción civil universal. Aunque ello relativice la voluntad prescriptiva jurídico-formal de los Estados sobre la jurisdicción civil universal, la aplicabilidad de las reglas de Derecho internacional privado es políticojurídicamente significativa al poder llegar a ocuparse de «situations entièrement localisées à l'étranger» (Bucher 2015, 100).

Si el Derecho internacional general parece no positivizar una norma jurídica que obligue a ejercer la jurisdicción civil universal frente a violaciones graves de derechos humanos, la tesis más ajustada parece ser que el ejercicio de la jurisdicción civil universal «is a permissive customary principle» (Donovan y Roberts, 2006; 143). No obstante, el Instituto de Derecho Internacional (IDI) ha matizado que, aunque no se puedan «affirmer des obligations strictes à la charge des États» (IDI 2017, 419), el derecho de acceso a un tribunal «s'oppose à toute application d'une règle de droit interne qui aboutit à un déni de Justice» (IDI 2017, 415).

Esto último supone que la evolución del desarrollo del ordenamiento jurídico internacional sobre las consecuencias jurídicas de las vulneraciones graves de los derechos humanos y los derechos de las víctimas ofrece otros parámetros para delimitar las obligaciones jurídicas internacionales de los Estados. En el reconocimiento jurídico internacional del derecho de acceso a la justicia, en particular para las víctimas de violaciones graves de derechos humanos, convergen, desde los 80 , la práctica regulatoria estatal, las disposiciones de tratados internacionales de carácter universal y regional y la práctica institucional de las Organizaciones internacionales competentes. No parece ilógico, pues, su integración en el Derecho internacional general cuando menos como uno de los «principios generales del Derecho reconocidos» en el foro doméstico y en el Derecho internacional de los derechos humanos (Abellán 1999, 214). En definitiva, se está ante una obligación erga omnes de Derecho internacional general (Bucher 2015, 77) ${ }^{30}$.

30 Según el IDI, una obligación erga omnes es aquella «that a State owes in any given case to the international community, in view of its common values and its concern for compliance, so that a breach of that obligation enables all States to take action» (Resolution on Obligations and rights erga omnes in international law, 27 August 2005, art. 1 a). 
El interrogante es cómo articular coherentemente esta obligación jurídica internacional erga omnes, con el compromiso jurídico permisivo del ejercicio de la jurisdicción civil universal que se desprende del Derecho internacional general, partiendo de que su ejercicio «has the potential to provide a mechanism through which to provide victims of international crimes with a right of access to justice» (Hovell 2018, 454).

Los Principios y directrices básicos sobre el derecho de las víctimas de violaciones manifiestas de las normas internacionales de derechos humanos y de violaciones graves del derecho internacional humanitario ${ }^{31}$ perfilan el deber de ofrecer a las víctimas «un acceso equitativo y efectivo a la justicia», incluida la debida reparación (Punto 3, c) y d)). El Punto 12 sugiere dos parámetros para su configuración jurídica: 1) el ordenamiento jurídico internacional es un referente necesario de la articulación interna del derecho a la justicia (la configuración jurídica de la jurisdicción civil universal como permisiva se adecua entonces circularmente conforme a la práctica estatal); y 2) es asumible un tratamiento jurídico no homogéneo del alcance y extensión de la jurisdicción estatal para hacerlo efectivo ${ }^{32}$.

EI IDI, al posicionarse en Tallin sobre la jurisdicción universal para la reparación de los denominados crímenes internacionales ${ }^{33}$, señaló el derecho de las víctimas a una adecuada y efectiva reparación y al acceso a los tribunales para obtenerla, con independencia de «any criminal conviction of the author of the crime» (artículo 1,2 y 1,3). Aunque se mantiene que son los tribunales del Estado donde se produjeron los hechos los que deberían ejercer su competencia, la percepción de la existencia de una obligación colectiva de los Estados propugna formalizar alternativas conectivas excepcionales para evitar la denegación de justicia (IDI 2017, 418), cuando «a) no other State has stronger connections with the claim, taking into account the connection with the victims and the defendants and the relevant facts and circumstances; or b) even though one or more other States have such stronger connections, such victims do not have available remedies in the courts of any such other State» (artículo 2,1).

31 Resolución 60/147, de la Asamblea General de la ONU, de 16 de diciembre de 2005.

32 Principio 12: "La víctima de una violación manifiesta de las normas internacionales de derechos humanos (...) tendrá un acceso igual a un recurso judicial efectivo, conforme a lo previsto en el derecho internacional (...). Las obligaciones resultantes del derecho internacional para asegurar el derecho al acceso a la justicia y a un procedimiento justo e imparcial deberán reflejarse en el derecho interno».

33 Resolution on Universal Civil Jurisdiction with regard to Reparation for International Crimes, 20 August 2015. 
En consecuencia, la obligación jurídica erga omnes de Derecho internacional general plantea una responsabilidad colectiva para garantizar a la víctima de violaciones graves de derechos humanos de un recurso efectivo para reclamar ante los tribunales de algún Estado, sin que ello redunde en que la víctima pueda elegir alternativamente entre varios foros. Esta obligación jurídica internacional revierte en un compromiso solidario (Bucher 2015, 78), en el que la instauración por un Estado de la justicia civil universal resultaría idónea para cumplir con sus compromisos ante la Comunidad internacional.

Esta dirección regulatoria atemperaría la discrecionalidad inherente a la permisividad de implementación de la jurisdicción civil universal, por la necesidad de su concordancia con una obligación jurídica positiva de Derecho internacional general que exige la no denegación de justicia a la víctima: compatibilizándola con las necesidades de las relaciones interestatales, se plantea que «l'exercice de la compétence universelle ne puisse pas être rendu impossible en raison d'une volonté d'abstention des Etats à fournir aux victimes l'accès à la Justice» (Bucher 2015, 103). El IDI, acorde con su Resolución de Tallin, asume esta visión: sin identificar obligaciones jurídicas estrictas y absolutas respecto al ejercicio de la jurisdicción civil universal, afirma que es esperable que los tribunales internos ejerzan «leur compétence pour procurer un accès effectif à la justice» (IDI 2019, 30).

La lógica jurídica hasta aquí reflejada se enfrenta —véanse los ejemplos de práctica estatal y los previos comentarios sobre la misma (Apartado II, 1) - a la mediatización del alcance extraterritorial por otras normas jurídicas internacionales aplicables de aquellos mecanismos que, directa o indirectamente, pueden vehicular estas reclamaciones civiles.

La persistencia en el Derecho internacional general de inmunidades de jurisdicción para el Estado y sus agentes ${ }^{34}$ (y, en su caso, también de ejecución) viene siendo un vector restrictivo para el ejercicio extraterritorial de la jurisdicción estatal frente a violaciones graves de derechos humanos, aun cuando la misma se circunscriba a actos de iure imperii, ya que impide continuar con la acción civil a diferencia de lo que acontece con personas físicas o jurídicas no amparadas por estas inmunidades. Vista la más que relativa implantación de

34 Para el Tribunal Supremo canadiense, el término «government» en la State Immunity Act (que exceptúa a los Estados que apoyan el terrorismo) incluye «public officials, being necessary instruments of the state», resultando de aplicación a los actos de tortura (actos de Estado) la inmunidad jurisdiccional del Estado (Kazemi Estate v. Islamic Republic of Iran, 2014 SCC 62, [2014] 3 S.C.R. 176, en 182). 
mecanismos de justicia civil universal, la operatividad subsidiaria del Derecho internacional privado se resiente por ello parcialmente como instrumento para evitar la denegación de justicia.

Apreciando que las normas jurídicas sobre ambas instituciones forman parte del Derecho internacional general, critica Bucher la prevalencia de la inmunidad de jurisdicción - medio de defensa ante las jurisdicciones estatales - frente a la necesidad de evitar la denegación de justicia; según él, queda mucho camino por recorrer para que las consideraciones basadas en la soberanía estatal no determinen la denegación de justicia para las víctimas «devant toute juridiction étrangère» (Bucher 2015, 92).

\section{El Derecho internacional privado como fundamento del ejercicio extraterritorial de la jurisdicción civil}

La percepción de que, en Derecho internacional público, «there is no special regime for obtaining a remedy for a violation of an international human rights norm by another State or that State's official» promueve que "such actions must be pursued in accordance with private international law» (Fawcett et al. 2016, 8).

El Derecho internacional privado ofrece alternativas para afirmar la competencia de los tribunales civiles y facilitar la disponibilidad de mecanismos coincidentes, funcional y teleológicamente, con los presupuestos de la jurisdicción civil universal. Las soluciones de Derecho internacional privado, empero, no suelen ser incondicionales ante los intereses políticos, compromisos jurídicos internacionales y/o las tradiciones jurídicas estatales (calificables como legítimas): se tiende a exigir alguna conexión con el foro, desvirtuando la equivalencia con la competencia universal pura, no facilitándose el acceso a la jurisdicción civil «for the sole reason that a claim was for a human rights violation, irrespective of any other connection to the jurisdiction» (International Law Association 2012, 7).

Esta aproximación requiere aludir sucintamente a la instrumentalidad del Derecho internacional privado y específicamente al foro de necesidad.

\subsection{La instrumentalidad del Derecho internacional privado ante violaciones graves de derechos humanos}

No debe desconocerse que la Conferencia de La Haya sobre Derecho Internacional Privado trabajó entre los años 1998-2001 en 
un tratado internacional, la Convention on Jurisdiction and Foreign Judgments in Civil and Commercial Matters, que contenía disposiciones extraterritoriales sobre "the exercise of jurisdiction by national courts in a way that affects cases seeking civil reparations for violations of human rights norms» (Van Schaack 2001, 171).

El debate en el Comité Especial (Van Schaack 2001, 182-189) derivó en un texto consolidado a finales de 1999 (Proyecto de Octubre), con dos redacciones alternativas del artículo 18,3, contemplando ambas el acceso a la jurisdicción civil por asuntos relativos a los derechos humanos como excepción a los criterios prohibitivos de fundamentación de la jurisdicción (The Hague Conference on Private International Law 2000a, 9-10):

3. Nothing in this Article shall prevent a court in a Contracting State from exercising jurisdiction under national law in an action [seeking relief] [claiming damages] in respect of conduct which constitutes:

Variant One:

(a) genocide, a crime against humanity or a war crime, [as defined in the Statute of the International Criminal Court; or]

[b) a serious crime against a natural person under international law; or]

[c) a grave violation against a natural person of non-derogable fundamental rights established under international law, such as torture, slavery, forced labour and disappeared persons].

[Sub-paragraphs [b) and] c) above apply only if the party seeking relief is exposed to a risk of a denial of justice because proceedings in another State are not possible or cannot reasonably be required.]

\section{Variant Two:}

[a serious crime under international law, provided that this State has established its criminal jurisdiction over that crime in accordance with an international treaty to which it is a party and that the claim is for civil compensatory damages for death or serious bodily injury arising from that crime].

No se pretende imponer una obligación jurídica al Estado sino permitirle ejercer su jurisdicción (Bucher 2015, 100). Si, en la variante 1, la posible denegación de justicia para reclamaciones por violaciones graves de los derechos humanos - excepto los constitutivos de crímenes de Derecho internacional- es una justificación expresa de la competencia, en la variante 2 (propuesta china), se supedita el ejercicio de la jurisdicción civil respecto a la comisión de conductas que en un 
tratado internacional del que el Estado es Parte se prevea el ejercicio de la jurisdicción penal y concurran daños de un cierto nivel de gravedad. Son fórmulas flexibles y abiertas - no incluyen una listado cerrado de actos justificativos de la excepción-, más bien identificativas de categorías de normas jurídicas internacionales constitutivas de violaciones graves de derechos humanos; la primera variante, empero, ofrece "an open-ended and exemplary list of norms that support the exercise of civil universal jurisdiction» (Van Schaack 2001, 189).

Las dificultades sustantivas y técnicas del proyecto, «politically sensitive» (Haines 2002, 167) —por ejemplo, debido a la incorporación del comercio electrónico-, pospusieron la celebración de una Conferencia Diplomática decisoria (The Hague Conference on Private International Law 2000, 12), malográndose el proyecto (Teitz 2019, 495-496)35; del mismo se derivaron el Convenio sobre Acuerdos de Elección de Foro, de 30 de junio de 2005, y, más tardíamente, el Convenio sobre el Reconocimiento y Ejecución de Sentencias en Materia Civil y Mercantil, de 2 de julio de 2019.

En torno a la práctica estatal, cabe señalar brevemente que:

a) Los vínculos que determinan el acceso ordinario a la jurisdicción civil (foro ordinario) no suelen favorecer el conocimiento universal de la responsabilidad civil por violaciones graves de derechos humanos ${ }^{36}$, excepto cuando, por ejemplo, el domicilio de la persona física presuntamente responsable se ubique en el Estado del foro o en este radique o domicilie una empresa matriz con un nivel de control operacional suficiente sobre los hechos acaecidos.

La práctica holandesa y británica (véase Apartado II) parte de la aplicación del Reglamento 1215/2012 (antes del Reglamento 44/2001) y cuyo foro general corresponde al domicilio del demandado en un Estado miembro (artículo 4) ${ }^{37}$. Estas «personas

35 «In February 2002, the U.S. announced that it would not continue with a comprehensive jurisdiction and recognition and enforcement convention», aunque sus reticencias no fueran perceptibles desde un inicio, sino desde "the emergence of the internet and electronic commerce, the increasingly prominent role of the consumer, and the rather rapid integration of the European Community» (Teitz 2019, 495).

36 "Les fors ordinairement accessibles, en matière délictuelle ou de «torts», sont fondés, soit sur le domicile du défendeur, respectivement le siège de l'entreprise défenderesse, soit sur le lieu de l'acte illicite ou du fait dommageable, respectivement sur l'activité du défendeur dans le rayon de juridiction du tribunal saisi» (Bucher 2015, 93).

37 Respecto a derechos laborales derivados del contrato individual de trabajo, su art. 20,2 afirma la jurisdicción de los tribunales del Estado miembro aunque el empresario con el que se firme el contrato no tenga domicilio en ningún Estado miembro (si dispone de sucursal, agencia o establecimiento). 
domiciliadas en un Estado miembro solo podrán ser demandadas ante los órganos jurisdiccionales de otro Estado miembro en virtud de las normas establecidas en las secciones 2 a 7» del Capítulo II (artículo 5,1). En materia de responsabilidad extracontractual ${ }^{38}$, como sucede respecto a las «acciones por daños y perjuicios o de acciones de restitución fundamentadas en un acto que diere lugar a un procedimiento penal» (artículo 7,3) 39 , no parece este foro general aplicarse a actos cometidos sin conexión con el espacio comunitario.

La no siempre fácil justificación fáctica de esta vía hace lógica la crítica a la no inclusión de un foro de necesidad en el Reglamento 1215/2012 (Álvarez Torné 2014, 437)40.

Es remarcable, sin embargo, su valor prospectivo para abordar la responsabilidad civil de las empresas, siendo "an important next step on a path that leads from soft law standards concerning the social responsibilities» empresariales (Enneking 2014, 53).

b) La operatividad de los foros subsidiarios, perfilados a partir de la proximidad de las partes y de los hechos litigiosos (Bucher 2015, 96), suele ofrecer soluciones difícilmente generalizables para este tipo de víctimas - presencia en el Estado de bienes del potencial demandado ${ }^{41}$ - o que resultan excepcionales - residencia temporal o la simple presencia del potencial demandado (Bucher 2015, 96-100).

c) La vinculación de la responsabilidad civil a la acción penal parece implicar (véase el modelo del artículo 5 CAT) una limitación al ejercicio de la jurisdicción por hechos cometidos fuera de la jurisdicción estatal (que la víctima sea nacional del

38 Art. 7,2: «En materia delictual o cuasidelictual, ante el órgano jurisdiccional del lugar donde se haya producido o pueda producirse el hecho dañoso».

39 Las acciones se plantearán "ante el órgano jurisdiccional que conozca de dicho proceso, en la medida en que, de conformidad con su ley, dicho órgano jurisdiccional pueda conocer de la acción civil».

40 A diferencia del art. 7 del Reglamento (CE) n. ${ }^{\circ}$ 4/2009 del Consejo, de 18 de diciembre de 2008, relativo a la competencia, la ley aplicable, el reconocimiento y la ejecución de las resoluciones y la cooperación en materia de obligaciones de alimentos; o del art. 11 del Reglamento (UE) n. ${ }^{\circ}$ 650/2012 del Parlamento Europeo y del Consejo, de 4 de julio de 2012, relativo a la competencia, la ley aplicable, el reconocimiento y la ejecución de las resoluciones, a la aceptación y la ejecución de los documentos públicos en materia de sucesiones mortis causa y a la creación de un certificado sucesorio europeo.

${ }^{41}$ Un ejemplo de foro exorbitante por la relatividad de sus vínculos con el Estado del foro. 
Estado, pero siempre que este lo considere apropiado) o que el presunto autor se encuentre en el propio territorio ${ }^{42}$.

d) En ausencia de foros de protección especial que amparen a las víctimas o de la disponibilidad de mecanismos de reclamación civil colectiva —class actions - que sustenten una aproximación litigiosa universalista, parece que el foro de necesidad, pese a su excepcionalidad, resulta el más próximo al objetivo de universalidad, siendo aplicable ante «circunstancias extraordinarias que no permiten el juego en de los criterios jurisdiccionales normales» para evitar la denegación de justicia (Fernández Rozas 2017, 243).

\subsection{El foro de necesidad y la competencia respecto a la acción civil}

Aunque su fundamento jurídico sea garantizar el derecho de acceso a los tribunales, no es una institución jurídica de Derecho internacional general (Bucher 2015, 105), porque difícilmente la práctica estatal proyecta una clara convicción sobre su obligatoriedad (Mora 2018, 180).

El foro de necesidad, primero, es un correctivo a otras reglas de competencia de Derecho internacional privado por las cuales el juez estatal resultaría incompetente (IDI 2019, 26-28).

$Y$, segundo, no es un foro exclusivo para acciones civiles por violación grave de los derechos humanos, sino un estándar relativo a la jurisdicción sobre controversias civiles y mercantiles, como demuestran los ALI/UNIDROIT Principles of Transnational Civil Procedure (ALII UNIDROIT Principles): "the forum of necessity whereby a court may properly exercise jurisdiction when no other forum is reasonably available» ${ }^{43}$. Su aplicabilidad, empero, responde sustancialmente a exigencias implícitas en la idea de jurisdicción civil universal (Bucher 2015, 105), siendo destacable su (incompleta) alternatividad frente a la ausencia de mecanismos estatales que instituyan específicamente la jurisdicción civil universal.

42 El art. 23,4 b) de la Ley Orgánica del Poder judicial española (LOPJ) señala que serán competentes los tribunales penales españoles por hechos cometidos fuera de territorio español: cuando «el procedimiento se dirija contra un español» o «la víctima tuviera nacionalidad española en el momento de comisión de los hechos y la persona a la que se impute la comisión del delito se encuentre en territorio español».

43 Commentary P2C Principle 2.2. (Principios y comentarios disponibles en: https://www.unidroit.org/instruments/transnational-civil-procedure. Acceso 30 diciembre 2019). 
En el Proyecto de Resolución del IDI sobre Human Rights and Private International Law, antes de abordar el foro de necesidad (artículo 9), el artículo 8,1 señala que: «Human rights, particularly the right of access to a court and the right to a fair hearing, do not require legislators or courts to base jurisdiction on particular heads of jurisdiction in international cases». Esta apelación al ejercicio directo (universal) de la competencia, según su párrafo 2, no niega que los Estados puedan condicionar su ejercicio, siempre que respondan a fines legítimos (IDI 2019, 72).

Las causas de la denegación de justicia pueden derivar tanto del no funcionamiento de los tribunales del Estado inicialmente competente — «impossibilité d'ouvrir action» debido a un conflicto armado u otros motivos de fuerza mayor (Retornaz y Volders 2008, 42)—, como de la insuficiente coordinación de los ordenamientos jurídicos de los Estados involucrados (IDI 2019, 27). Los obstáculos que impiden a la víctima acceder a los tribunales de Estados con vínculos objetivos más sólidos con ella o con los hechos, pese a su diversidad terminológica, pueden sintetizarse (véase nota 40) en la imposibilidad de que un procedimiento pueda razonablemente introducirse o llevarse a cabo en y ante otros foros estatales, o que el mismo resulte imposible en un Estado tercero con el cual el litigio tiene estrecha relación.

La exigibilidad jurídica de una causa excepcional constituirá una primera condición para recurrir al foro de necesidad.

El ejercicio del foro de necesidad puede someterse a otras condiciones: el artículo 9 del Proyecto de Resolución del IDI las perfila genéricamente demandando "a sufficient connection with the State of the court seized» (IDI 2019, 72). La conexión suficiente, conforme a los ALI/UNIDROIT Principles (Principio 2.2.), se concreta en criterios específicos: la presencia del demandado en el Estado del foro; el vínculo de nacionalidad del demandado con el Estado del foro; o la presencia de propiedades del demandado en el Estado del foro. Aunque este tipo de criterios caracteriza la práctica estatal44, Estados como los Países Bajos no prescriben ni exigen conexión alguna ${ }^{45}$.

La convergencia de la práctica estatal no elimina la ausencia de uniformidad en aras de la coordinación de jurisdicciones (International

44 En España, el art. 22 octies LOPJ establece que: «Los Tribunales españoles no podrán abstenerse o declinar su competencia cuando el supuesto litigioso presente vinculación con España y los Tribunales de los distintos Estados conectados con el supuesto hayan declinado su competencia».

45 La no exigencia de conexión en el caso japonés — no mencionado previamentees de origen jurisprudencial (International Law Association 2012, 16 y 18, y Nota 145). 
Law Association 2012, 18-19), ya que son los tribunales estatales quienes interpretan la suficiencia conectiva, determinando la preponderancia del casuismo judicial (Rossolillo 2010, 410).

El foro de necesidad suizo es un ejemplo de traslación a los tribunales de la interpretación del alcance de la conexión suficiente, en este caso con la causa, conforme al artículo 3 de la Loi Fédérale sur le droit international privé (LDIP) ${ }^{46}$, siendo objeto de un litigio ante el TEDH respecto al artículo 6 (derecho de acceso a los tribunales) del Convenio Europeo para la Protección de los Derechos Humanos y de las Libertades Fundamentales (CEDH).

Admitida la incompetencia de los tribunales suizos a tenor de otras disposiciones de la LDIP y constatada la imposibilidad de interponer un procedimiento en otro Estado o no poderle ser exigida razonablemente al demandante esa opción, el Tribunal Federal Suizo (TFS) interpretó de modo restrictivo la noción de causa: descartó que existiese conexión suficiente debido al vínculo de la persona con Suiza y determinó que los hechos «de la cause ne présentent donc aucun lien avec la Suisse», pues «le demandeur se plaint d'actes de torture qui auraient été commis en Tunisie, par des tunisiens domiciliée en Tunisie, à l'encontre $d^{\prime}$ un tunisien résidant en Italie» ${ }^{47}$.

No existiendo una obligación jurídica internacional de implantar la jurisdicción civil universal por tortura, la Gran Sala del TEDH entendió que la declaración de incompetencia del TFS y su interpretación de la conexión suficiente no vulneraban el artículo 6 CEDH, porque ${ }^{48}$ : 1) los criterios restrictivos del foro de necesidad eran comunes entre los Estados: y 2) la interpretación sobre el alcance del foro de necesidad no era ni arbitraria ni manifiestamente irrazonable, tanto por los fines legítimos alegados ${ }^{49}$ como por su proporcionalidad.

46 «Lorsque la présente loi ne prévoit aucun for en Suisse et qu'une procédure à l'étranger se révèle impossible ou qu'on ne peut raisonnablement exiger qu'elle y soit introduite, les autorités judiciaires ou administratives suisses du lieu avec lequel la cause présente un lien suffisant sont compétentes» (Conseil Fédéral, Loi fédérale sur le droit international privé (LDIP), du 18 décembre 1987. Acceso 7 febrero 2020, https://www. admin.ch/opc/fr/classified-compilation/19870312/index.html\#fn-\#a129-2.).

47 Tribunal Fédéral, 22.05.2007 4C.379/2006. § 3.5.

Al demandante, asilado en Suiza desde 1995, le fue concedida la nacionalidad suiza pocos meses después de la sentencia; había iniciado una acción penal infructuosa contra el Ministro del Interior de Túnez por ser allí objeto de tortura.

48 ECHR, Naït-Liman v. Switzerland [GC], no. 51357/07, párs. 217-220, ECHR 2018.

49 El Estado refirió distintos problemas: la disponibilidad de prueba determinante sobre hechos sucedidos en Túnez; la ejecución de la decisión; la prevención legítima del fórum shopping y el efecto llamada (aumento de la carga de trabajo de los tribunales); y la limitación de futuras desavenencias diplomáticas. 
Las críticas señalan cómo «the Court structured the proportionality analysis in such a way that state interests did not merely outweigh, but essentially displaced those of victims» (Hovell, 2018: 26), en detrimento de los derechos e intereses de la víctima (Loudon 2018,4). El peso de los fines legítimos esgrimidos por el Estado —entre ellos, la hipotética generación de un forum shopping en caso de mayor flexibilidadfueron relevantes para el TEDH.

Aunque no corresponde al TEDH ofrecer «a liberal interpretation of a specific jurisdictional technique on a Contracting Party, where the majority of Contracting Parties do not even use such a technique» (Ryngaert 2017, 806), el fallo no parece apoyarse en «una argumentación jurídica bastante sólida para llegar a este resultado» (Lloret 2019, 60).

Primero, en torno a la interrelación jurisdicción civil universal/foro de necesidad que emplea el TEDH, existente funcional y materialmente porque el litigio se refiere a una violación grave de derechos humanos, cabe decir:

a) Además de relativa, ya que el tratamiento argumental y jurídico de ambas instituciones es diferenciado, parece orientada más bien a ampliar el margen de apreciación otorgado para justificar la declinatoria: tras negar la existencia de una obligación jurídica internacional de implementar la jurisdicción civil universal por tortura, se afirma que el Estado dispone de un amplio (wide) margen de apreciación. La pregunta es si se precisaba esta interrelación para llegar a tal conclusión: ¿no es probable que per se el margen de apreciación fuese amplio respecto a la aplicación de una institución de Derecho internacional privado? ¿Qué margen de apreciación se hubiese otorgado de existir la obligación jurídica internacional sobre la jurisdicción civil universal?

b) La pretendida convergencia teleológica y político-jurídica entre la jurisdicción civil universal y el foro de necesidad se olvida al fijar particularmente el alcance de este margen de apreciación, circunscribiéndose el análisis a la cuestión jurídico-formal de la existencia o no de una obligación jurídica internacional -algo aparentemente incoherente con la remisión a las reglas interpretativas de los artículos 31 a 33 CVDT-. El problema no es tanto la insuficiente consideración de la prohibición de la tortura como norma imperativa de Derecho internacional ${ }^{50}$ — véase la

50 El juez Dedov afirmara que la sentencia era contraria al ius cogens (Dissenting opinión of Judge Dedov, p. 77 (ECHR, Naït-Liman v. Switzerland [GC], no. 51357/07, ECHR 2018)). 
posición de la CIJ sobre la inmunidad jurisdiccional—, sino que la redacción e interpretación del foro de necesidad impiden admitir a trámite una acción civil por actos de tortura (no por otro tipo de causa), cuando la significación político-jurídica del asunto quizá hubiese aconsejado un margen de apreciación más limitado. La vehemente crítica del juez Dedov ${ }^{51}$ significó que los valores subyacentes debían prevalecer y relativizar la importancia del consenso y del test de razonabilidad del margen de apreciación.

$Y$, segundo, es perceptible la facilidad con que se omite un debate profundo sobre la cuestión crucial relativa a la proporcionalidad: ¿la decisión judicial tiene como resultado o no la denegación de justicia respecto a una acción civil por actos de tortura? La Gran Sala del TEDH asume rápidamente la tesis suiza de que el término causa hace mención a un set of facts con los que debe establecerse la conexión suficiente de los tribunales suizos; siempre examinándose en el material time anterior al inicio del procedimiento judicial, de modo que ninguna modificación posterior de la situación resultase parte de la causa ni justificase una conexión suficiente: por ejemplo, que Naït-Liman residiera en Suiza y hubiese solicitado la ciudadanía suiza cuando introdujo la demanda ${ }^{52}$. Se tiene, además, por un elemento no decisivo la lógica de que «the material time for a court to decide whether it has jurisdiction should be when the question arises»53; quizá apoyándose en que los actos lesivos objeto del litigio no constituían una situación continuada que permitiese extender el material time. La debilidad de la argumentación deviene de la centralidad causal dada a los actos de tortura frente al verdadero foco material de la causa examinada: las consecuencias jurídicas de los actos de tortura - por ejemplo, la exigencia de una indemnización justa — susceptibles de justificar una acción civil o incluso el mismo acto de interponerla ${ }^{54}$.

\section{Consideraciones finales}

La implementación y el ejercicio de la jurisdicción civil universal respecto a violaciones graves de derechos humanos no constituye una

51 Ibid. p. 75.

52 Naït-Liman v. Switzerland [GC], no. 51357/07, párr. 212 y 213, ECHR 2018.

53 Disenting opinión of Judge Serghides, p. 92, (Nait-Liman v. Switzerland [GC], no. 51357/07, ECHR 2018).

54 El art. 28 octies LOPJ señala también que: «Los Tribunales españoles apreciarán, de oficio o a instancia de parte, su competencia de conformidad con las normas vigentes y las circunstancias concurrentes en el momento de presentación de la demanda (pár. 2)». 
obligación jurídica de Derecho internacional general, en ausencia de una práctica estatal suficientemente generalizada y de una convicción jurídica sobre su obligatoriedad. Las exigencias jurídicas y la práctica derivadas de tratados internacionales de carácter universal y específico - particularmente, CAT y CDF- no están exenta de incertidumbres y de debate.

A la permisividad respecto a la articulación de la jurisdicción civil universal, se le sobrepone el reconocimiento jurídico internacional del derecho a la justicia, proyectado con especial significación políticojurídica respecto a las víctimas de violaciones graves de derechos humanos. Un equilibrio entre la facultad de los Estados para articular la jurisdicción civil universal y el principio general del derecho de garantizar el derecho a la justicia, evitando la denegación de justicia, se concreta en el compromiso colectivo y solidario de garantizar el acceso a los tribunales civiles de las víctimas, si no es posible en el Estado de los hechos o en Estados con mayor relación con los mismos. Es obvio que ello admite una pluralidad de formas individualizadas $y / o$ de lagunas en la ejecución del esfuerzo solidario.

Las instituciones de Derecho internacional privado pueden contribuir subsidiaria y significativamente, por su objeto, a la tentativa de lograr ese equilibrio. Más allá del modelo estadounidense, existen (pocas) experiencias satisfactorias, por ejemplo, en Europa, a partir de normas jurídicas de Derecho de la Unión Europea y/o de normas jurídicas internas, que permiten plantear judicialmente la responsabilidad civil, sobre todo, de empresas transnacionales; la inmunidad jurisdiccional del Estado y de sus agentes juegan y pueden seguir jugando, según cómo evolucione su interpretación, una restricción real al efectivo acceso a la justicia civil.

El foro de necesidad es una institución jurídica, bien que de naturaleza excepcional, que teleológica y materialmente se aproxima a los parámetros político-jurídicos de la jurisdicción civil universal porque pretende evitar la denegación de justicia. Como demuestra la práctica estatal referenciada, así como la sentencia de la Gran Sala del TEDH, su instrumentalidad depende de cómo se configuren e interpreten los requerimientos que determinan su activación.

La sentencia de la Gran Sala del TEDH en el asunto Naït-Liman $v$. Suiza es representativa de la paradoja instrumental del foro de necesidad: el condicionamiento de su efecto útil a la forma en que se establezcan e interpreten las condiciones de ejercicio -en especial, la suficiencia de la conexión con el foro-. Sin considerar el resultado irrazonable, los argumentos justificativos del TEDH no deslumbran por su profundidad: no se pondera suficientemente la conexión 
teleológica y funcional del foro de necesidad con hechos que denotan la vulneración de la prohibición de la tortura (norma imperativa de Derecho internacional) y que redundan en la denegación a la víctima del acceso a la justicia; además, el amplio margen de apreciación otorgado al Estado parece más vinculado a la valoración de los fines legítimos esgrimidos por aquel (¿se priorizó cercenar la vis atractiva para víctimas con tenues vínculos con Suiza?), que con la constatación de la relevancia instrumental del foro de necesidad en ausencia de obligación jurídica internacional sobre la jurisdicción civil universal.

\section{Bibliografía}

Abellán, Victoria. 1999. "La aportación de las UN a la internacionalización del derecho a la justicia». En Los Derechos Humanos en un mundo dividido, 209-226. Bilbao: Universidad de Deusto.

Álvarez Torné, María. 2014. "La protección de los derechos humanos en el proceso de internacionalización de las empresas». En Las medidas preventivas de conflictos jurídicos en contextos económicos inestables, editado por Xavier Lluch, 421-438. Barcelona: Editorial Bosch.

Besner, Jennifer y Amir Attaran. 2008. "Civil liability in Canada's courts for torture committed abroad: The unsatisfactory interpretation of the State Immunity Act 1985 (Can)». Tort Law Review, 16: 150-167.

Bright, Claire. 2019. "The Civil Liability of the Parent Company for the Acts or Omissions of Its Subsidiary: The Example of the Shell Cases in the UK and in the Netherlands». In Business and Human Rights in Europe, editado por Angelica Bonganti. 212-222. Londres: Routledge.

Brus, Marcel. 2014. "lus Humanitatis and the Right to Reparation for International Crimes in Foreign Domestic Courts». International Criminal Law Review, 14: 358-376.

Bucher, Andreas. 2015. "La compétence universelle civile». Recueil Des Cours de l'Acadèmie de Droit International / Collected Courses of the International Law Academy, 372: 1-127.

Burgers, Herman y Hans Danelius. 1988. The United Nations Convention: A Handbook on the Convention and Other Cruel, Inhuman or Degrading Treatment or Punishment. Londres: Martinus Nijhoff Publishers.

CDI. 2014. «Segundo informe sobre la identificación del derecho internacional consuetudinario por Michael Wood, Relator Especial». Documento A/ CN.4/672, 22 de mayo de 2014.

CDI. 2016. «Identificación del derecho internacional consuetudinario. Texto de los proyectos de conclusión aprobados provisionalmente por el Comité de Redacción». Documento A/CN.4/872, 30 de mayo de 2016.

Cleveland, Sarah H. 2010. «Embedded International Law and the Constitution Abroad». Columbia Law Review, 110: 225-287. 
Comisión de Derechos Humanos. 2006. «Informe sobre el 37. período de sesiones (2 de febrero a 13 de marzo de 1981)». Documento E/CN.4/2006/57, 2 de febrero de 2006.

Comité de Derechos Humanos. 2001. "Observación general N. ${ }^{\circ} 29$. Estados de emergencia (artículo 4)». Documento CCPR/C/21/Rev.1/Add.11, 31 de agosto de 2001.

Comité contra la Tortura. 2002. "Queja N. ${ }^{\circ}$ 176/2000. Marcos Roitman Rosenmann v. España. Decisión de 30 de abril de 2002». En Informe del Comité contra la Tortura $27^{\circ}$ período de sesiones (12 a 23 de noviembre de 2001) y $28^{\circ}$ período de sesiones (29 de abril a 17 de mayo de 2002). Documento A/57/44, 204-214.

Comité contra la Tortura. 2012a. «Examen de los informes presentados por los Estados partes en virtud del artículo 19 de la Convención. Observaciones finales del Comité contra la Tortura Canadá». Documento CAT/C/CAN/ CO/6, 25 de junio de 2012.

Comité contra la Tortura. 2012b. "Observación general N. 3 (2012). Aplicación del artículo 14 por los Estados partes». Documento CAT/C/GC/3, 13 diciembre de 2012.

Comité contra la Tortura. 2015. "Queja N. ${ }^{\circ} 511 / 2012$. N. v. Australia. Decisión de 26 de noviembre de 2014». Documento CAT/C/53/D/511/2012, 19 enero de 2015.

Comité contra la Tortura. 2016. «Examen de los informes presentados por los Estados partes en virtud del artículo 19 de la Convención con arreglo al procedimiento facultativo de presentación de informes. Séptimos informes periódicos que los Estados partes debían presentar en 2016. Canadá». Documento CAT/C/CAN/7, 13 de septiembre de 2016.

Donovan, Donald y Anthea Roberts. 2006. "The Emerging Recognition of Universal Civil Jurisdiction». American Journal of International Law, 100: 142-163.

Enneking, Liesbeth. 2014. "The Future of Foreign Direct Liability? Exploring the International Relevance of the Dutch Shell Nigeria Case». Utrecht Law Review, 10: 44-54.

Fawcett, James, Máire Shúilleabhaín y Sangeeta Shah. 2016. Human Rights and Private International Law. Oxford: Oxford University Press.

Fernández Rozas, José Carlos. 2017. «Rigidez versus flexibilidad en la ordenación de la competencia judicial internacional: el forum necessitatis». En Desarrollos Modernos del Derecho Internacional Privado. Libro Homenaje al Dr. Leonel Pereznieto Castro, coordinado por Víctor Rojas, 229-285. México: Tirant lo Blanch.

Ferrer, Jorge. 2019. «La jurisdicción civil universal ante el Derecho Internacional -y su relación con la jurisdicción penal universal-. A propósito de NaïtLiman v. Switzerland». Revista General de Derecho Europeo, 47: 1-47.

Haines, Avril. 2002. "Why is it so difficult to construct an international legal framework for e-commerce? The Draft Hague Convention on Jurisdiction and the Recognition and Enforcement of Foreign Judgments in Civil and 
Commercial Matters: A case study». European Business Organization Law Review, 3: 157-194.

Hall, Christopher. 2007. "The duty of States parties to the Convention against Torture to provide procedures permitting victims to recover reparations for torture committed abroad». European Journal of International Law. 18: 921-937.

Hovell, Devika. 2018. "The authority of universal jurisdiction». LSE Law, Society and Economy Working Papers 8/2018, 1-32. Londres: London School of Economics and Political Science.

IDI. 2017. Droits de l'homme et droit international privé. Hyderabad: Rapport de la $4^{\mathrm{ème}}$ commission (Rapporteur: Jürgen Basedow). Acceso 15 enero 2020. http://www.idi-iil.org/app/uploads/2017/06/4eme_com.pdf.

IDI. 2019. Droits de l'homme et droit international privé. La Haye: Rapport de la 4 ème commission (Rapporteur: Jürgen Basedow). Acceso 15 enero 2020. http://www.idi-iil.org/app/uploads/2019/06/Commission-4-Droits-deIhomme-et-droit-international-prive-Basedow-Travaux-La-Haye-2019.pdf

International Law Association. 2012. "International Civil Litigation and the Interest of the Public. (Final Report)». Report of the Sixty Fifth Conference (Sofia 2012). Acceso 16 enero 2020. https://ila.vettoreweb.com/Storage/ Download.aspx?DbStorageld=1118\&StorageFileGuid=59f7e403-77334f8c-822d-e58b9be0d02b.

Jägers, Nicola, Katinka Jesse y Jonathan Verschuuren. 2014. "The future of corporate liability for extraterritorial human rights abuses: The Dutch case against Shell». American Journal of International Law. 1: 36-41.

Kolb, Robert. 2003. "Selected problems in the theory of customary International Law». Netherlands International Law Review, 50: 119-150.

Loudon, Charlie. 2018. «Right of access to a court in civil claims for torture committed abroad: The European Court Grand Chamber Decision in NaïtLiman». EJIL Talk!, Blog of the European Journal of International Law, April 3, 2018. Acceso 12 de febrero 2020. https://www.ejiltalk.org/rightof-access-to-a-court-in-civil-claims-for-torture-committed-abroad-theeuropean-court-grand-chamber-decision-in-nait-liman/.

Marullo, Maria y Francisco Zamora. 2018. «El alien tort statute y las consecuencias del caso Kiobel en los litigios transnacionales sobre empresas y derechos humanos». En Empresas y Derechos Humanos, editado por Maria Marullo y Francisco Zamora, 225-248. Napoli: Editoriale Scientifica.

Mora, Paul. 2009. "The legality of civil jurisdiction over torture under the Universal Principle». German Yearbook of International Law. 52: 367403.

Mora, Paul. 2018. "Universal Civil Jurisdiction and Forum Necessitatis: The confusion of Public and Private International Law in Naït-Liman v. Switzerland». Netherlands International Law Review. 65: 155-183

Nowak, Manfred. 2007. «Torture and enforced disappareances». In International Protection of Human Rights: A Textbook, editado por Catarina Krause y Martin Scheinin, 151-182. Turku: Åbo Akademi University Institute for Human Rights. 
Requejo, Marta. 2007. «Transnational human rights claim y acceso a la jurisdicción civil en Europa». Revista de Derecho Comunitario Europeo. 27: 511-548.

Retornaz, Valentin y Bart Volders. 2008. «Le for de nécessité: tableau comparatif et évolutif». Revue Critique de droit international privé. 97 : 229-261.

Rossolillo, Giulia. 2010. «Forum necessitatis e flessibilità dei criteri di giurisdizione nel Diritto internazionales privatto nazionale e dell'Unione Europea». Cuadernos de Derecho Transnacional, 2: 403-418.

Ryngaert, Cedric. 2007. "Universal tort jurisdiction over gross human rights violations». Netherlands Yearbook of International Law. XXXVIII: 3-60.

Ryngaert, Cedric. 2017. "From Universal Civil Jurisdiction to Forum of Necessity. Reflections on the Judgment of the European Court of Human Rights in Nait-Liman». Rivista di diritto internazionale. 100: 782-807.

Teitz, Louise (2019). "Another Hague Judgements Convention? Bucking the past to provide for the future». Duke Journal of International \& Comparative Law. 29 : 491-511.

The Hague Conference on Private International Law. 2000. "Conclusions of the Special Commission of May 2000 on General Affairs and Policy of the Conference». Document Prel. Doc. No 10, June 2000. Acceso 21 enero 2020. https://assets.hcch.net/docs/52fa2d6b-b582-4ca0-a373-3ca6e29aecc7.zip.

US Senate. 1990. Convention and Other Cruel, Inhuman or Degrading Treatment or Punishment. Report of Mr. Pell, from the Committee on Foreign Relations. Executive Report 101-30, 101st Congress, 2d Session, 30 August 1990.

Van Schaack, Beth. 2001. «In defense of civil redress: The domestic enforcement of human rights norms in the context of the proposed Hague Judgments Convention». Harvard International Law Journal. 42: 141-200.

Wind, Marlene. 2018. International Courts and Domestic Politics. Cambridge: Cambridge University Press. 


\section{Copyright}

Deusto Journal of Human Rights / Revista Deusto de Derechos Humanos is an Open Access journal; which means that it is free for full and immediate access, reading, search, download, distribution, and reuse in any medium only for non-commercial purposes and in accordance with any applicable copyright legislation, without prior permission from the copyright holder (University of Deusto) or the author; provided the original work and publication source are properly cited (Issue number, year, pages and DOI if applicable) and any changes to the original are clearly indicated. Any other use of its content in any medium or format, now known or developed in the future, requires prior written permission of the copyright holder.

\section{Derechos de autoría}

Deusto Journal of Human Rights / Revista Deusto de Derechos Humanos es una revista de Acceso Abierto; lo que significa que es de libre acceso en su integridad inmediatamente después de la publicación de cada número. Se permite su lectura, la búsqueda, descarga, distribución y reutilización en cualquier tipo de soporte sólo para fines no comerciales y según lo previsto por la ley; sin la previa autorización de la Editorial (Universidad de Deusto) o la persona autora, siempre que la obra original sea debidamente citada (número, año, páginas y DOI si procede) y cualquier cambio en el original esté claramente indicado. Cualquier otro uso de su contenido en cualquier medio o formato, ahora conocido o desarrollado en el futuro, requiere el permiso previo por escrito de la persona titular de los derechos de autoría. 